\title{
A multiport MR-compatible neuroendoscope: spanning the gap between rigid and flexible scopes
}

\author{
*Sunil Manjila, MD, Margherita Mencattelli, PhD, Benoit Rosa, PhD, Karl Price, MS, \\ Georgios Fagogenis, MSc, and Pierre E. Dupont, PhD \\ Department of Cardiovascular Surgery, Boston Children's Hospital, Harvard Medical School, Boston, Massachusetts
}

\begin{abstract}
OBJECTIVE Rigid endoscopes enable minimally invasive access to the ventricular system; however, the operative field is limited to the instrument tip, necessitating rotation of the entire instrument and causing consequent tissue compression while reaching around corners. Although flexible endoscopes offer tip steerability to address this limitation, they are more difficult to control and provide fewer and smaller working channels. A middle ground between these instruments-a rigid endoscope that possesses multiple instrument ports (for example, one at the tip and one on the side) -is proposed in this article, and a prototype device is evaluated in the context of a third ventricular colloid cyst resection combined with septostomy.
\end{abstract}

METHODS A prototype neuroendoscope was designed and fabricated to include 2 optical ports, one located at the instrument tip and one located laterally. Each optical port includes its own complementary metal-oxide semiconductor (CMOS) chip camera, light-emitting diode (LED) illumination, and working channels. The tip port incorporates a clear silicone optical window that provides 2 additional features. First, for enhanced safety during tool insertion, instruments can be initially seen inside the window before they extend from the scope tip. Second, the compliant tip can be pressed against tissue to enable visualization even in a blood-filled field. These capabilities were tested in fresh porcine brains. The image quality of the multiport endoscope was evaluated using test targets positioned at clinically relevant distances from each imaging port, comparing it with those of clinical rigid and flexible neuroendoscopes. Human cadaver testing was used to demonstrate third ventricular colloid cyst phantom resection through the tip port and a septostomy performed through the lateral port. To extend its utility in the treatment of periventricular tumors using MR-guided laser therapy, the device was designed to be MR compatible. Its functionality and compatibility inside a 3-T clinical scanner were also tested in a brain from a freshly euthanized female pig.

RESULTS Testing in porcine brains confirmed the multiport endoscope's ability to visualize tissue in a blood-filled field and to operate inside a 3-T MRI scanner. Cadaver testing confirmed the device's utility in operating through both of its ports and performing combined third ventricular colloid cyst resection and septostomy with an endoscope rotation of less than $5^{\circ}$.

CONCLUSIONS The proposed design provides freedom in selecting both the number and orientation of imaging and instrument ports, which can be customized for each ventricular pathological entity. The lightweight, easily manipulated device can provide added steerability while reducing the potential for the serious brain distortion that happens with rigid endoscope navigation. This capability would be particularly valuable in treating hydrocephalus, both primary and secondary (due to tumors, cysts, and so forth). Magnetic resonance compatibility can aid in endoscope-assisted ventricular aqueductal plasty and stenting, the management of multiloculated complex hydrocephalus, and postinflammatory hydrocephalus in which scarring obscures the ventricular anatomy.

http://thejns.org/doi/abs/10.3171/2016.7.FOCUS16181

KEY WORDS neuroendoscopy; optical window; silicone cap; chip-on-the-tip camera; side-firing camera; MR-compatible endoscope

ABBREVIATIONS CCD = charge-coupled device; CMOS = complementary metal-oxide semiconductor; CSF = cerebrospinal fluid; ETV = endoscopic third ventriculostomy; LED = light-emitting diode.

SUBMITTED May 2, 2016. ACCEPTED July 1, 2016.

INCLUDE WHEN CITING DOI: 10.3171/2016.7.FOCUS16181.

* Drs. Manjila and Mencattelli contributed equally to this work. 
$\mathrm{T}$ HE primary clinical use for endoscopes in neurosurgery is the treatment of hydrocephalus, either primary or secondary. ${ }^{18,23}$ Secondary hydrocephalus can occur from tumors or cysts located within the ventricular system, rendering them suitable for endoscopic resection or fenestration to treat both the lesion and the resultant hydrocephalus. ${ }^{39,61,95}$ Rigid endoscopes are commonly used to perform endoscopic third ventriculostomy (ETV) in treating hydrocephalus, obviating the need for ventriculoperitoneal shunt placement, especially in obstructive hydrocephalus. In complex loculated hydrocephalus, ETV is also combined with septostomy. In lesions such as colloid cysts or in scarring of the unilateral foramen of Monro causing asymmetrical hydrocephalus, a septostomy forms the mainstay of endoscopic management. Sometimes loculated or encysted hydrocephalus is treated with extensive endoscopic adhesiolysis or wide fenestrations, followed by ventriculoperitoneal shunt placement if deemed necessary. ${ }^{1,76}$ The use of flexible neuroendoscopes is best illustrated by the combined procedure of ETV with choroid plexus coagulation. ${ }^{13,44,82}$ This steerable technique is also applicable in multiloculated hydrocephalus associated with ex vacuo atrophy or encystment of the periventricular brain parenchyma. To achieve optimum results, the use of a steerable endoscope is highly advisable to reach around corners during ETV combined with posterior third ventricular-pineal region tumor biopsy. ${ }^{6,14}$ Endoscopic intraventricular biopsy of a tumor in obstructive hydrocephalus helps to obtain a histological diagnosis along with emergency cerebrospinal fluid (CSF) diversion, contrary to a risky stereotactic transcranial biopsy in the setting of persistent intracranial tension. Intuitively, direct vision during a biopsy can reduce the chance of procedural hemorrhages and allows one to instantly and safely address them as and when they occur. ${ }^{16}$

Straight endoscopes provide imaging and working channels only at the instrument tip, leading to several limitations in their use. First, it is not possible to image or operate tools at an angle with respect to the endoscope axis, which makes it impossible to work around corners. Second, reorientation of the endoscope axis requires rotation of the entire instrument about a pivot point located at the bur hole. This motion can cause the instrument shaft to press against adjacent brain tissue, leading to potential deformational injury to vital periventricular brain structures such as the fornices. ${ }^{2,5}$ Flexible scopes address the orientation limitation of straight endoscopes by providing a steerable tip mounted on a compliant shaft; however, they typically have fewer and smaller instrument channels than the straight endoscopes. Furthermore, since the proximal length is passive, care must be taken to avoid brain tissue damage from pressure or abrasion caused by the shaft. These instruments are used by fewer surgeons and involve additional skills training to hold the tip position; to maneuver thinner, flexible instruments; and, above all, to avoid disorientation during zoomed-in views. ${ }^{14,58,98}$

One method of gaining some of the benefits of steerable endoscopes while maintaining the operational simplicity of a straight endoscope is through the use of multiple imaging and/or tool ports within a single endoscope shaft offering an internal radius of curvature. With such a device, imaging ports could be positioned at the instrument tip, as well as anywhere and at any angle along the endoscope body. If imaging and illumination are accomplished using chip cameras and light-emitting diodes (LEDs), many imaging ports can be supported in a given-diameter instrument because of the small wiring size, while also producing an instrument that is much lighter and easier to manipulate than a standard rigid endoscope. Although the endoscope cross-section does limit the total number and size of the independent tool channels, these channels can be distributed or shared between imaging ports based on procedural requirements.

For example, the novel multiport neuroendoscope in Fig. 1 was designed for performing a colloid cyst resection combined with septostomy. ${ }^{17,45}$ The tip port combines irrigation and aspiration channels with 1 tool channel for colloid cyst dissection. A second port located on the side of the endoscope includes a single tool channel. This port can be used to perform a septostomy with minimal pivoting of the instrument shaft about the center of the bur hole. This endoscope design could also be used in lieu of a steerable endoscope for treating multiloculated hydrocephalus. The lateral port would enable extensive multiplanar fenestration of the fibrous septae, which could not be easily accessed by the tip port. Many design variations are possible. Figure 2A illustrates how several cameras can be positioned in the same port to provide multiple viewing angles simultaneously. Figure $2 \mathrm{~B}$ shows how instrument ports can be angled to achieve tool triangulation. Figure 2C illustrates a laterally oriented tip port with multiple tool channels. This multiport design could be safely employed in the tailored resection of posterior third ventricle tumors with minimal neurological morbidities.

While most neuroendoscopes are not MR compatible (see Güttler et al. ${ }^{31}$ for an exception), some procedures could benefit from combined endoscopic and MRI guidance. ${ }^{48,86}$ In the treatment of multiloculated hydrocephalus, for example, MRI can reveal the extent and direction of intraventricular septations and periventricular cavitations with respect to the nearest cisterns to enable fenestration of these optically occluded tissues, resulting in a functioning cystoventriculocisternostomy. ${ }^{88}$ Another potential application leveraging multiple endoscopic ports and MR compatibility is transventricular biopsy, resection, or laser ablation of periventricular lesions. This transventricular approach could be particularly beneficial in treating these multiple lesions since standardized ventricular access is faster and relatively safe, compared with more time-consuming preoperative planning necessary for transparenchymal access. In addition, endoscopic imaging could enhance effectiveness by providing optical imaging of tumor margins and improve safety by enabling real-time visualization of intraprocedural hemorrhage and tool-based hemostasis.

Another feature of the novel neuroendoscope proposed here is the soft, distal, silicone optical window used to encase our imaging ports (Fig. 1B). When a surgeon inserts a tool through a standard neuroendoscope, it becomes visible only after it exits the endoscope, creating a risk of iatrogenic injury if the tool inadvertently contacts eloquent brain tissue as it moves into view. The optically clear sili- 

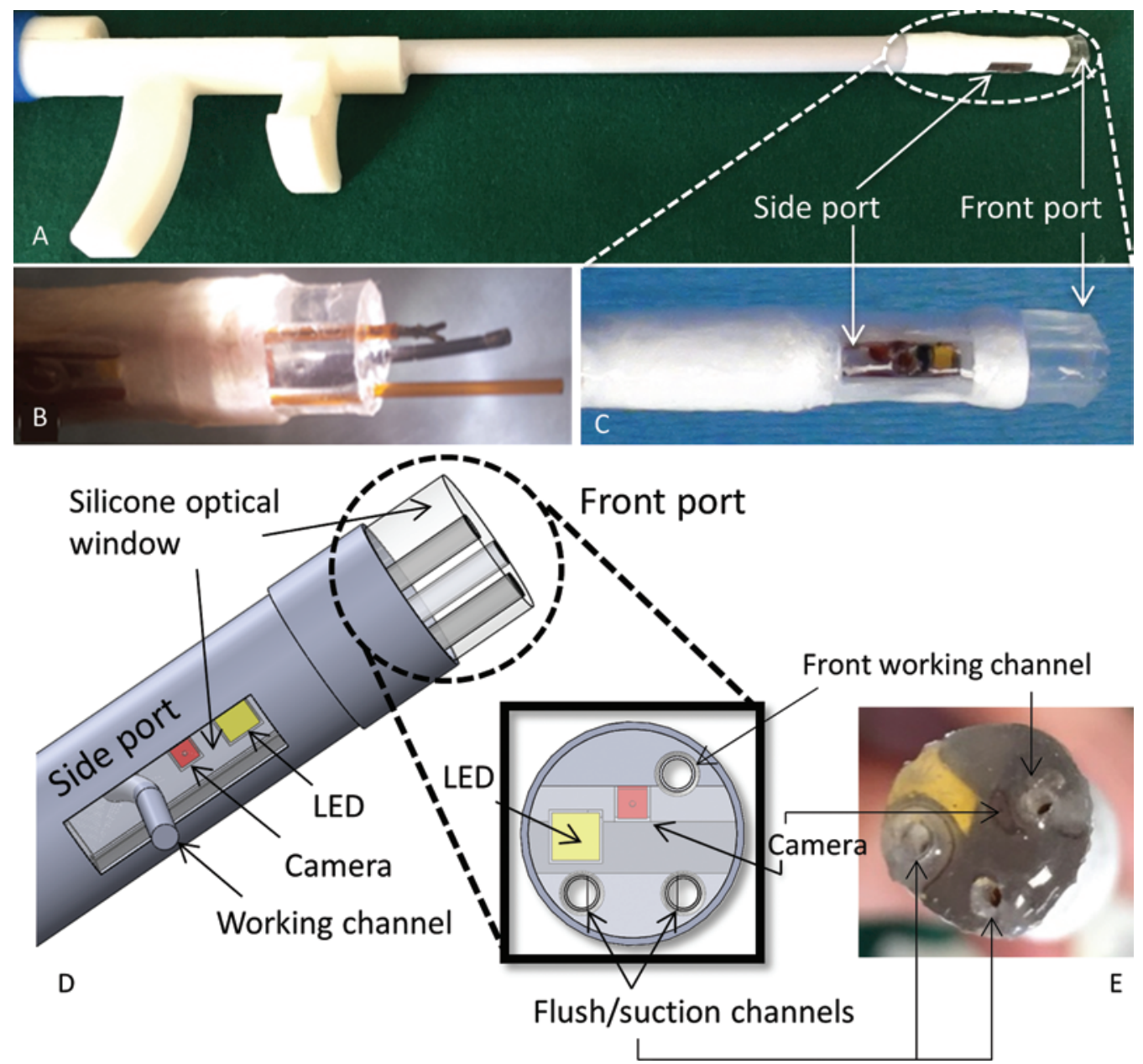

FIG. 1. Prototype of MR-compatible multiport neuroendoscope (A) with tip (B and $\mathbf{E}$ ) and side (C) ports. A computer-aided design (CAD) drawing (D) of the device showing the ports.

cone window enables initial tool visualization while the tool is passing through the window (Fig. 3A) and before it can make contact with tissue (Fig. 3B). With the clinical endoscopes currently in use, you can only see the tool when it has already extended out of the working channel (Fig. 3C). The soft clear window also makes it possible to safely visualize tissue in a blood-filled field. When the window is pressed lightly against tissue, the blood between the window and tissue is displaced to provide a clear view of the contacted tissue. This technique has been successfully shown to provide endoscopic guidance inside the blood-filled beating heart. ${ }^{4,30,90}$ In neuroendoscopy, this technique might be used to locate a hemorrhaging vessel.

In this study we present the design and evaluation of the 2-port MR-compatible neuroendoscope shown in Fig. 1. After designing and fabricating the device, we first examined its image quality using test targets positioned at clinically relevant distances from each imaging port. These experiments demonstrated how our multiple ports using chip cameras provide resolution and image quality in between those of flexible and rigid endoscopes. To appraise the ability to image through contact in a blood- filled field, ex vivo testing using porcine and human brains was performed. We next evaluated MR compatibility by testing the instrument inside a scanner and the ability to obtain MR images of tissue adjacent to the endoscope as well as to stream endoscope video inside the scanner. Finally, to determine the instrument's ability in the context of a multiport procedure, we performed a combined colloid cyst resection and septostomy in a cadaveric head.

\section{Methods \\ Endoscope Design}

The neuroendoscope (Fig. 1) was designed to provide 2 imaging ports enabling tissue resection at the tip port and electrocautery at the lateral port. The device has a total weight of less than $50 \mathrm{~g}$. The instrument body (7$\mathrm{mm}$ outer diameter) consists of a straight $150-\mathrm{mm}$-long plastic tube with a proximal ergonomic handle. The tip (Fig. 1D and E) and lateral (Fig. 1C and D) imaging ports each contain a $1 \times 1 \times 1-\mathrm{mm}$ complementary metal-oxide semiconductor $(\mathrm{CMOS})$ video camera $(250 \times 250$ pixels, NanEye, Awaiba Inc.) and an LED for illumination (1.6 $\times 1.6 \mathrm{~mm}$, Cree Inc.). The tip port contains three $1-\mathrm{mm}$ 


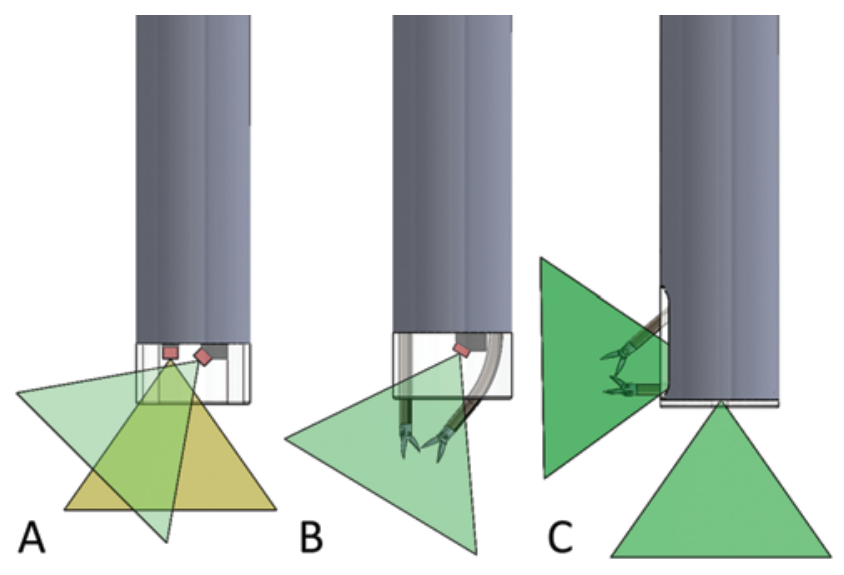

FIG. 2. Schematic of possible alternate locations for cameras and ports at any angle or site along the axis of the endoscope, with emerging tools to suit the nature and location of selected ventricular pathologies. Multiple cameras $\left(0^{\circ}\right.$ and $\left.45^{\circ}\right)$ at the same port (A), curved tool ports for instrument triangulation $(\mathbf{B})$, and bimanual instrument control through a lateral imaging port $(\mathbf{C})$.

channels positioned close to the corners of the camera frame of view (Fig. 1E). These working channels can be respectively used for tools, irrigation, and aspiration. The lateral port contains a single $1-\mathrm{mm}$ channel with a $7-\mathrm{mm}$ radius of curvature, which is sized to deliver a Bugbee wire to perform monopolar cautery for fenestration of the septum pellucidum. All channels are lined by $1.2-\mathrm{mm}-$ outer-diameter polyimide tubes.

Each imaging port is molded from optically clear silicone (QSil 218, Quantum Silicones LLC), which encapsulates the camera and LED while creating an optical window with a refractive index of $1.4^{57}$ (close to that of CSF at $1.33^{9}$ to minimize distortion). While the optical window of the lateral port is approximately $2 \mathrm{~mm}$ thick and molded to be flush with the instrument's cylindrical surface, the window of the tip port has been designed with a thickness of approximately $6 \mathrm{~mm}$. While a much thinner window can be substituted, this thickness was used to enable both visualization of inserted tools before they extend from the tip of the endoscope and safe tissue contact with concurrent imaging.

\section{Evaluation of Imaging}

Imaging of test targets was performed at multiple clinically relevant standoff distances (on contact and 5, 10, 15, and $20 \mathrm{~mm}$ ) at both the tip and lateral ports in saline. These distances were also examined using clinical straight rodlens and flexible neuroendoscopes. The USAF-1951 3-Bar Resolving Power Test Chart was used as a standard reference in all of our testing (Fig. 4). The target was printed on white paper using a 1200-dpi printer. (Since the smallest features are not printed clearly, a microscope view is also included in the figure.)

\section{MR Compatibility}

MR compatibility testing comprised 3 components: 1) testing for dangerous magnetic forces or torques as the device was introduced into and manipulated inside the scanner bore, 2) determining the size of any MRI artifacts produced by the device in surrounding tissue, and 3) ensuring normal operation of the cameras inside the scanner. Figure $5 \mathrm{~A}$ shows a schematic of the MRI testing. The cables ran from the camera and LED of the multiport endoscope to a laptop computer located in the MRI control room. The endoscope was first carefully manually inserted inside the scanner bore and then moved throughout the interior of the bore. Next, cephalic MRI was performed in a freshly euthanized adult female Yorkshire pig (Sus scrofa domesticus). After evaluating the brain anatomy, we transcranially advanced the endoscope through a prepositioned bur hole into a lateral ventricle inside the scanner bore (Skyra 3T, Siemens). Magnetic resonance images were acquired using standard T2-weighted FLAIR sequences. Separately, endoscope video sequences were acquired with and without simultaneous MR pulse sequence execution using the test targets to more easily detect any changes in image quality during scanning (Fig. 5B-D).

\section{Cadaver-Based Instrument Evaluation}

The Boston Children's Hospital Post Mortem Research Committee approved the use of human tissue for this study. After creating a frontal bur hole and cruciate durotomy on a human cadaver skull, we introduced an obturator through the underlying cortex into the brain parenchyma. This cavity was widened with suction and filled with
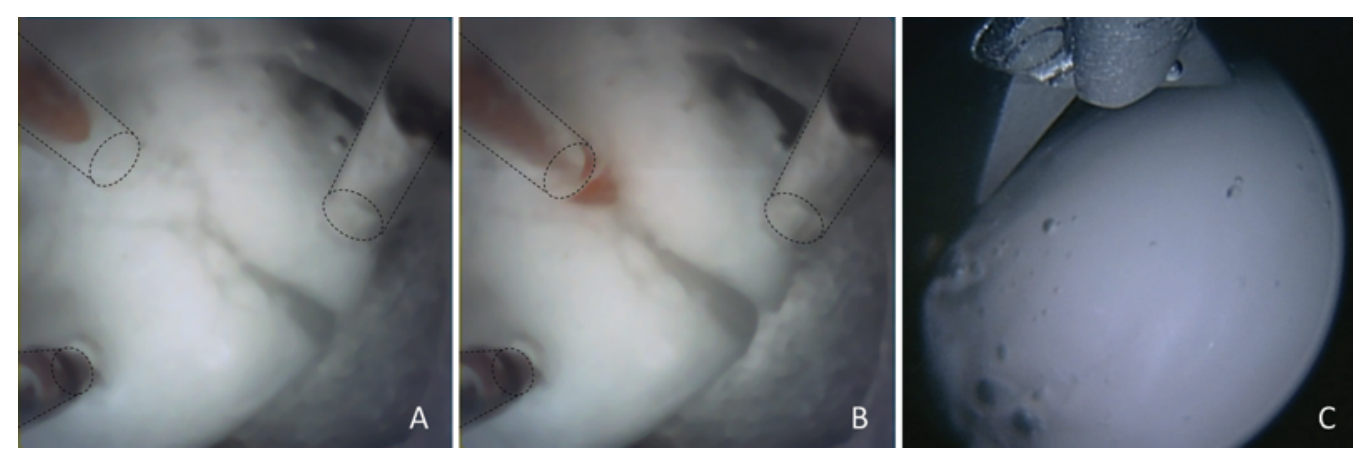

FIG. 3. Suction instrument emerging through the transparent working channel (left upper port) within the silicone optical window of the multiport endoscope. The instrument is inside the window $(\mathbf{A})$ and then has emerged (B). In comparison, when endoscopic scissors become visible in a current clinical endoscope, they have already emerged from the working channel (C). Dashed lines indicate working channels. 


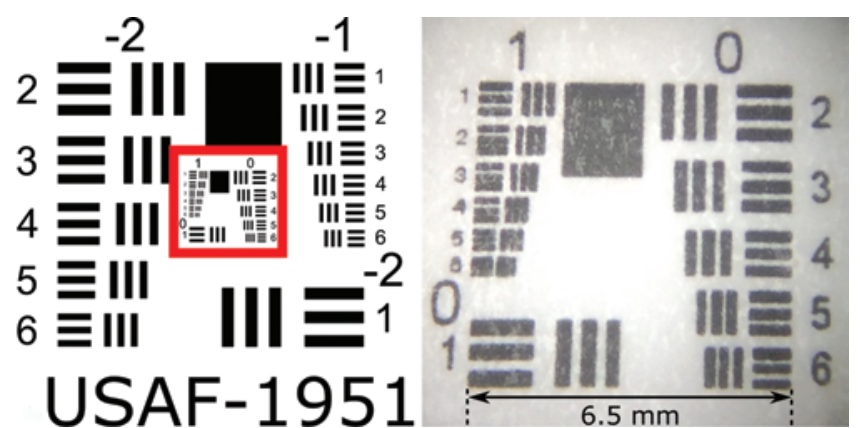

FIG. 4. USAF-1951 test target (left) showing the area of imaging interest outlined in red, and conventional microscopic imaging of the laminated test chart used during our experiments (right). Note that the diminished quality of the right image with a target size of $6.5 \mathrm{~mm}$ is attributable to our printer limitations.

blood, and the endoscope was introduced. To determine if the optical window would enable visualization during contact, we slowly advanced the scope until contact was made with the tissue. Given the fixed, shrunken, cadaveric ventricular anatomy, a 4-bur-hole craniotomy was made to implant an artificial colloid cyst transcallosally at the left foramen of Monro. To make the colloid cyst phantom, we dissolved $0.05 \%$ ultrapure agarose (Life Technolo- gies) in $1 \times$ phosphate-buffered saline (PBS) by boiling the mixture in a microwave oven and cooling it down to $45^{\circ} \mathrm{C}$ before adding cream cheese to produce the whitish color of the cyst contents. Immediately, the whole mixture was poured into stretched Parafilm (Bemis Co.) to simulate a colloid cyst with whitish viscous contents that could be readily aspirated. Septostomy was performed inside the cadaveric head using a Bugbee wire inserted through the lateral port of the new endoscope under direct vision. The scattered cadaver debris in the ventricles obscured the views for both a standard endoscope and the new multiport scope. Consequently, a phantom test bed was made in a clear, saline-filled container to perform cutting, suction, and irrigation on the colloid cyst phantom.

To measure the scope rotation needed to perform the combined procedure, we used an electromagnetic tracking system (3D Guidance trakSTAR, Ascension Technology Corp.). A tracking sensor was attached to the endoscope, allowing continuous recording of the instrument position and orientation (Fig. 6A). The pivoting angle with respect to the bur hole was measured for a case in which both procedures were performed via the tip port of the standard scope (Fig. 6B and C). The angle was also measured for the multiport scope when the tip port was used for cyst resection and the lateral port was used for septostomy (Fig. 6D).

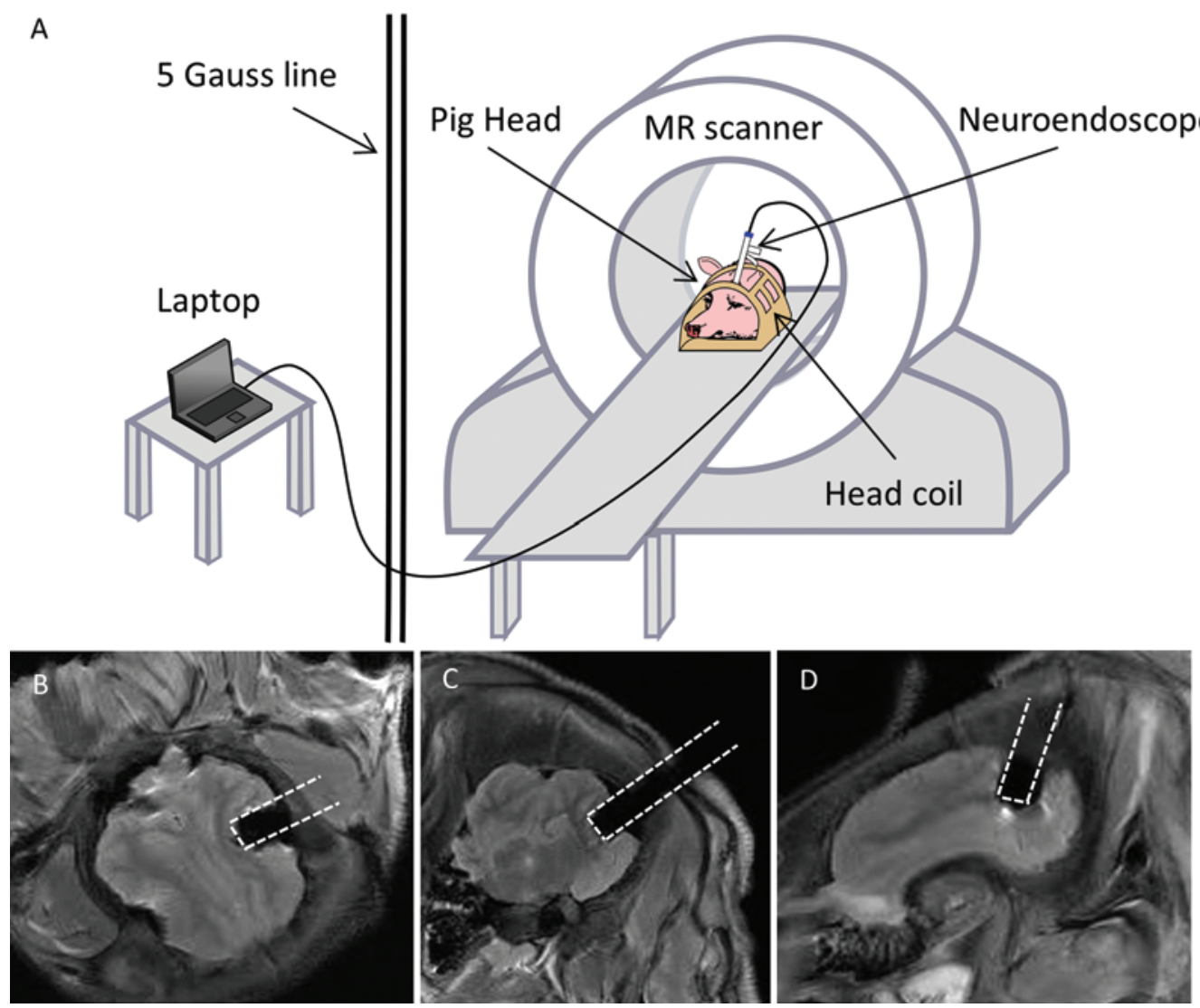

FIG. 5. A: Schematic of MRI testing, with the pig head positioned in the head coil while the neuroendoscope was inserted via a preplanned bur hole. B-D: Demonstration of the MR compatibility of the novel multiport endoscope without any significant artifacts using a fresh porcine brain. 

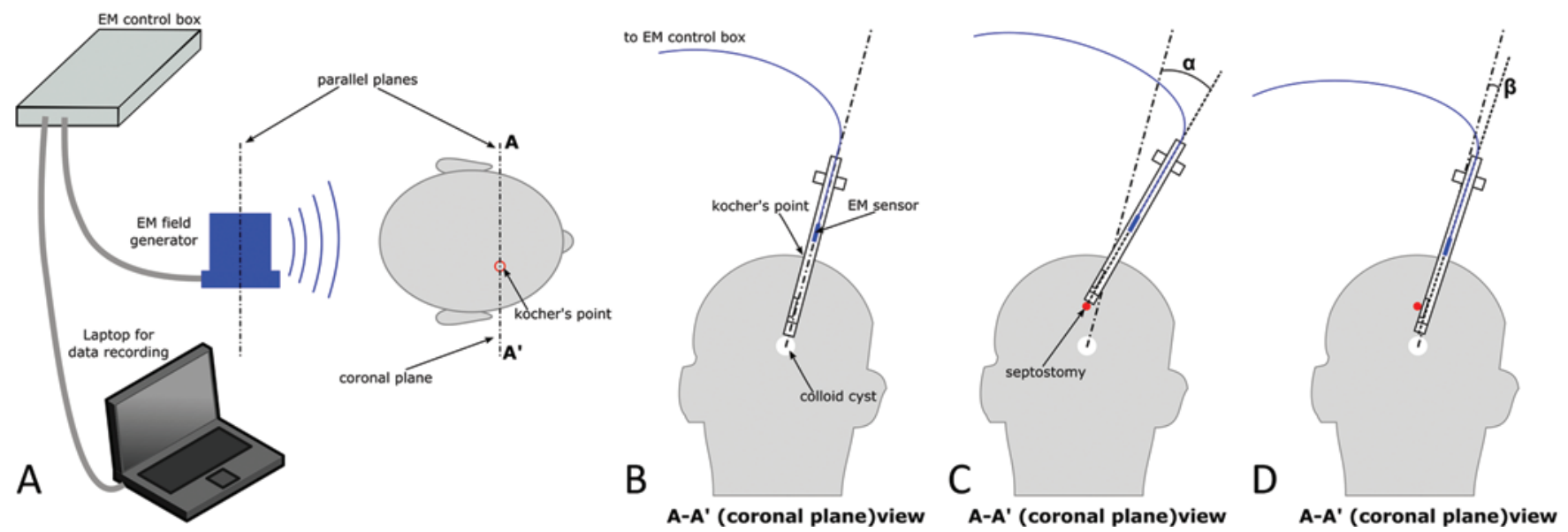

FIG. 6. Measurement of brain deformation during ventricular neuroendoscopy. Setup of the electromagnetic (EM) tracker (A), insertion path for the colloid cyst resection (B), instrument pivoting (measured by angle $\alpha$ ) required for septostomy using a standard rigid scope $(\mathrm{C})$, and pivoting (measured by angle $\beta$ ) required using a multiport endoscope (D).

\section{Results}

\section{Image Quality}

Image quality for the multiport scope was compared with that for the clinical rigid and flexible scopes (Fig. 7). Since fiber-based scopes are often used slightly defocused to avoid visualization of the boundaries of individual fibers, Fig. 7 provides both focused and defocused images for comparison. On contact, only the multiport scope provided a clear focused view. For all noncontact distances, the image quality of the multiport endoscope appeared to lie between those of the rigid scope and the flexible scope. Note that both clinical scopes have been optimized and refined during product development, whereas the multiport scope is a research lab prototype, which can probably be significantly improved.

\section{MR Compatibility in the Porcine Brain}

When the new neuroendoscope was inserted into the scanner and moved manually inside the bore, no magnetic forces were perceived. Furthermore, video streaming was unaffected by device placement inside the bore. Subsequently, pulse sequences were obtained during video streaming. We found that the radiofrequency (RF) portion of the pulses would sometimes interfere with video streaming. Since the camera cabling was not RF shielded, this interference is not surprising. Finally, images of the endoscope inside a porcine brain were recorded (Fig. 5B-D). The endoscope appears as a void in these images. Strikingly, while artifacts of instruments are often larger than the instruments themselves, the size of the new endoscope artifact corresponds exactly to its actual size.

\section{Cadaver-Based Instrument Evaluation}

The multiport endoscope's ability to visualize tissue through contact is illustrated in Fig. 8. As with a standard scope, nothing can be seen in a blood-filled cavity (Fig. $8 \mathrm{~A}$ ). Once soft contact with the tissue is made, however, the silicone optical window displaces the blood in front of the camera making clear visualization possible (Fig.
8B). Fenestration and/or aspiration of a colloid cyst phantom were first attempted in a cadaver brain. Owing to the shrunken ventricles and tissue debris, our attempts were not feasible with either the multiport or rigid scopes. Consequently, cyst removal was demonstrated in a phantom test bed. Endoscopic tip views of the classic skills of cutting, suction, and irrigation on the colloid cyst phantom are shown in Fig. 9. The lateral port was then used to perform septostomy, but inside the cadaver head, while maintaining a stable view of the anterior field near the colloid cyst phantom at the foramen of Monro as in Fig. 10A. Figure 10 elucidates the sequential steps of positioning the side port close to the septum (Fig. 10B), passing the Bugbee wire through the side port (Fig. 10C), firing the coagulation probe (Fig. 10D), and finally a view of the septostomy hole (Fig. 10E).

Using the electromagnetic tracking sensor, the scope tip was moved between the positions needed for cyst resection and septostomy by pivoting about the bur hole in the skull. The angle of rotation ( $\alpha$ in Fig. 6 ) was $23^{\circ}$, and significant compression of the tissue was observed in performing this rotation. Subsequently, the scope was rotated between the configurations appropriate for cyst resection using the tip port and for septostomy using the lateral port. The rotation angle ( $\beta$ in Fig. 6$)$ was $4.3^{\circ}$.

\section{Discussion}

The MR-compatible multiport endoscope technology proposed here combines several novel features. First, it introduces the concept of multiple imaging and instrument ports within the endoscope shaft. Second, it demonstrates how a transparent optical window can be used to view emerging tools and to image tissue clearly during soft contact. Third, it provides these features in an MR-compatible device. Since chip cameras are used instead of the heavier, bulkier charge-coupled device (CCD) cameras and rod lenses of standard rigid neuroendoscopes, the total weight of the multiport neuroendoscope is substantially reduced ( $45 \mathrm{vs} 150 \mathrm{~g}$ ). Furthermore, the weight of the proposed de- 
Contact
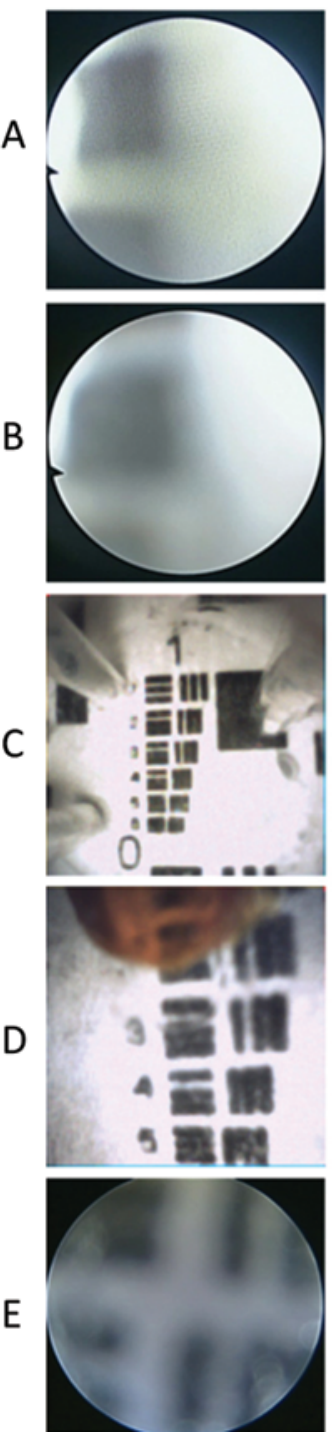

$5 \mathrm{~mm}$
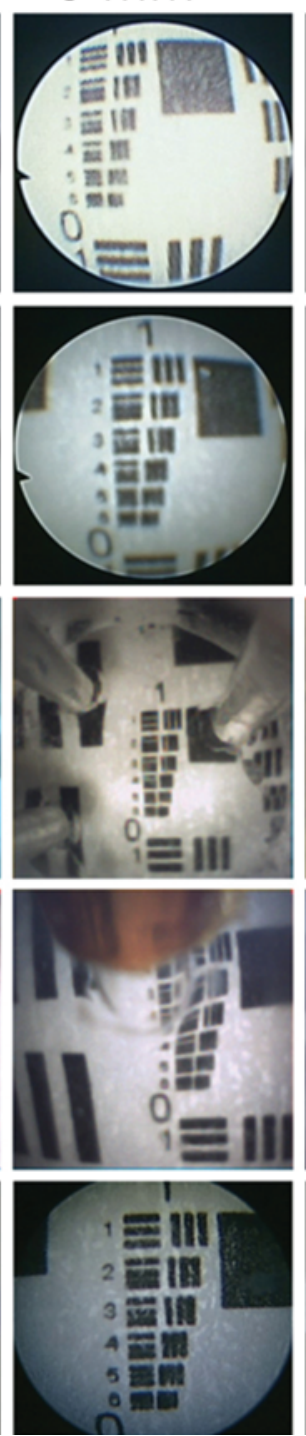

$10 \mathrm{~mm}$
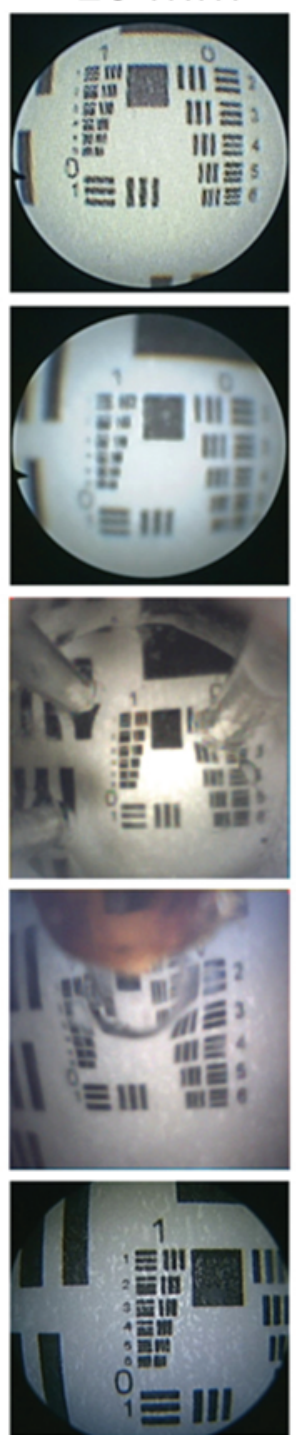
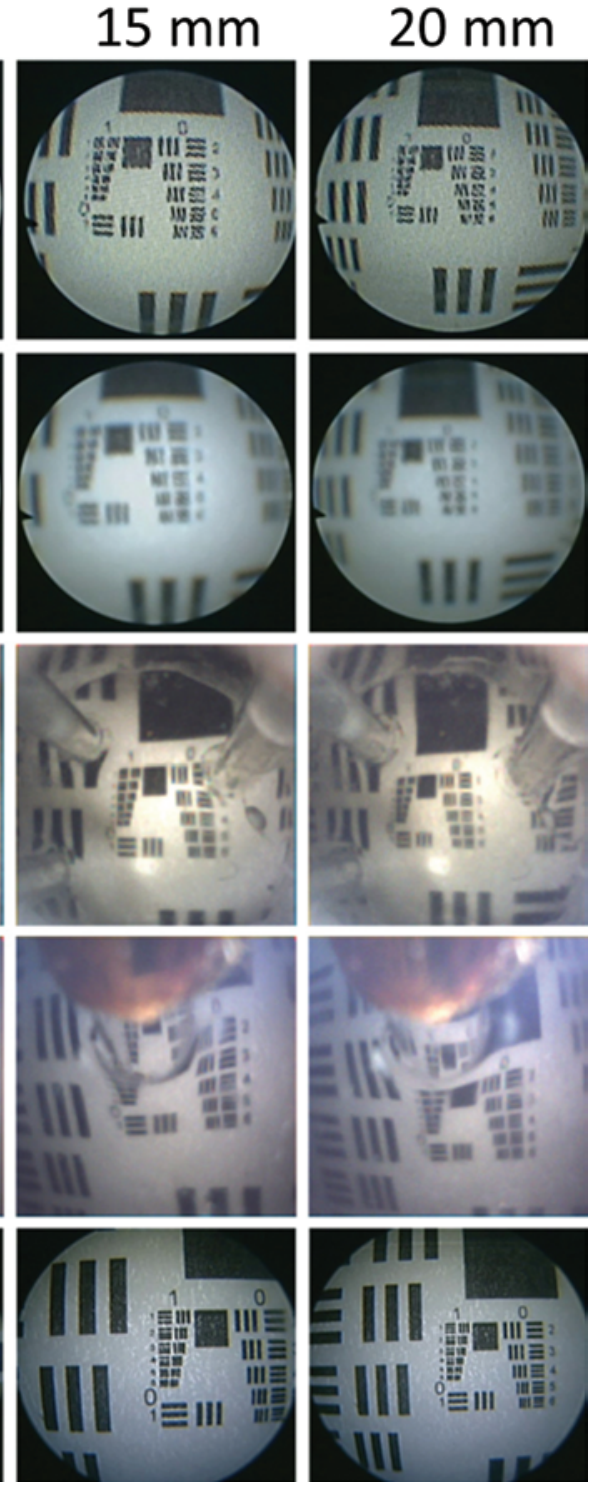
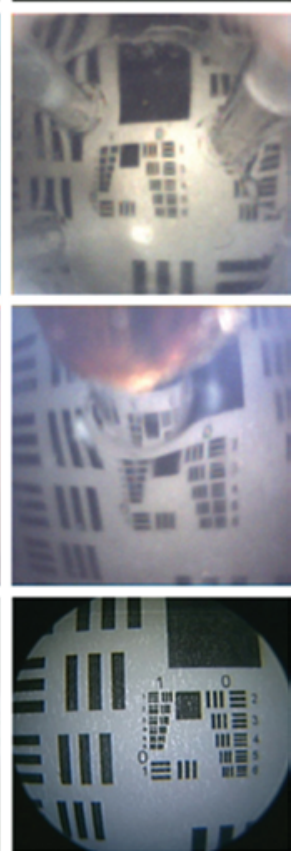

FIG. 7. Imaging results for the multiport neuroendoscope compared with those for the rigid and flexible neuroendoscopes in current clinical practice. A: Flexible neuroendoscope at contact and 5, 10, 15, and $20 \mathrm{~mm}$ (crisp). B: Flexible neuroendoscope at contact and 5, 10, 15, and $20 \mathrm{~mm}$ (blurred). C: Tip port images at contact and 5, 10, 15, and $20 \mathrm{~mm}$. D: Side port images at contact and 5, 10, 15, and $20 \mathrm{~mm}$. E: Rigid-lens straight endoscope images at contact and 5, 10, 15, and $20 \mathrm{~mm}$.

vice is evenly distributed along its length (Fig. 11 upper) in contrast to a rigid endoscope, which behaves as an inverted pendulum because of the weight of the proximally attached camera (approximately $250 \mathrm{~g}$ ) and the light cable (approximately 200 g; Fig. 11 lower). Thus, the multiport endoscope is much easier to manipulate and stabilize during surgery than existing models of rigid and flexible neuroendoscopes. In addition, the incorporation of multiple ports provides multidirectional imaging and tool deployment without the complexity of a flexible endoscope or wider parenchymal channels employed in port surgery or tubular retractors. ${ }^{25,27,51,59}$ Both front and side port imaging can be simultaneously performed, offering added safety for concurrent procedures, whereas the flexible scope tip can lead to disorientation after steering the tip 3 or 4 times in different directions, getting the operator lost in terms of the global field view. Thus, the disorientation experienced by the operator is much less using our endoscope compared with the steerable tip vision-induced disorientation from a flexible scope. An endoscope-positioning device for stabilization during surgery can prevent inadvertent movement of the shaft while instruments are extending through one or both ports. The low cost of the multiport endoscope avoids the need for a large capital investment and offers the potential for disposable use.

\section{Utility of Multiple Ports}

We have demonstrated the utility of 2 ports in performing a combined colloid cyst resection and septostomy. When the combined procedure is routinely performed 

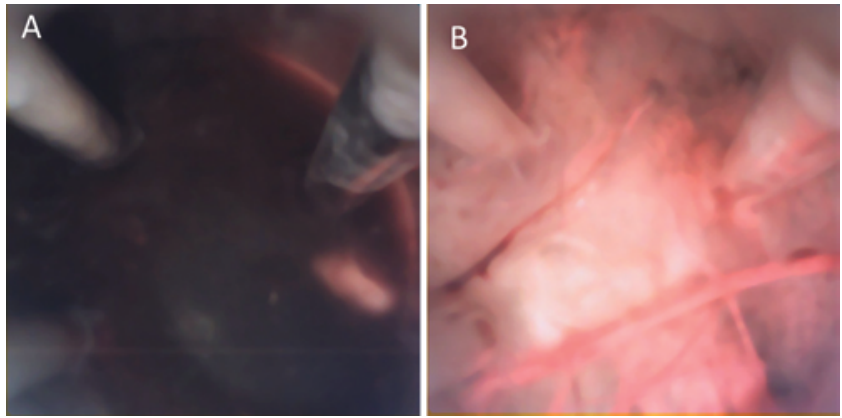

FIG. 8. Imaging in blood using the multiport neuroendoscope demonstrating the "diver's mask effect" of a soft silicone optical window. A: Noncontact view in the human cadaver brain cavity field filled with citrated porcine blood. B: View through the tip port after advancing the neuroendoscope to contact the tissue in a blood-filled cavity.

with a rigid endoscope, the endoscope's proximal inserted length compresses adjacent brain structures as the tip is redirected from the direction of the third ventricle at the foramen of Monro to the septal area devoid of veins. We have shown that the multiport endoscope's second port can substantially reduce this rotation $\left(23^{\circ}\right.$ vs $\left.4.3^{\circ}\right)$. Furthermore, since the septum contains a highly variable network of veins, the amount of endoscope rotation can be greater than the reported value since the septum must be explored to locate a vein-free location for perforation, especially during prophylactic septostomy in mild to moderate ventriculomegaly. ${ }^{92}$

The brain shift during ETV has been studied extensively. ${ }^{10,43,100}$ However, fenestration of the septum pellucidum has not been studied for quantitative brain deformation while using a standard precoronal bur hole for ETV or an adjusted bur hole for colloid cyst resection. The conventional scope is inserted in a trajectory for ETV or colloid cyst removal, then the endoscope itself distorts the brain medially when the scope is directed or forced toward the midline septum pellucidum, especially in cases with mild to moderate ventriculomegaly. ${ }^{25,32,87}$ We have used the septostomy as a prototypical procedure to show the utility of the side port for instruments and imaging, as the side port would allow direct access to the septum without significant brain deformation. Using this new multiport endoscope will facilitate safe resection of a lesion at the foramen of Monro while allowing one to identify a bleeding source in the lateral ventricle, and thus providing information on the focal field of surgery in real-time and augmenting the global view offered by intraoperative MRI. ${ }^{40,41}$

The combined use of flexible and rigid endoscopes as well as dual bur hole endoscopic procedures has been demonstrated in various ventricular pathologies, often in small-sized ventricles. $7,22,32,36,37,54,55,67,71,74,91,96,99$ Two classic indications for using our novel endoscope instead of existing rigid and flexible scopes are loculated, or postinflammatory, hydrocephalus and posterior third ventricular lesions. The multidirectional septations and adhesions in the ventricular system can be fenestrated or lysed easily and effectively by multiplanar multichannel instrumentation using this new endoscope. The multiport scope can offer better image delineation than the fiber bundles of flexible endoscopes with less potential for disorientation, the same compatibility with navigational devices, and no additional skill training for surgeons. As an extension of this application, our new scope can provide a better bird's eye view of the subependymal spread of disseminated ventricular tu-
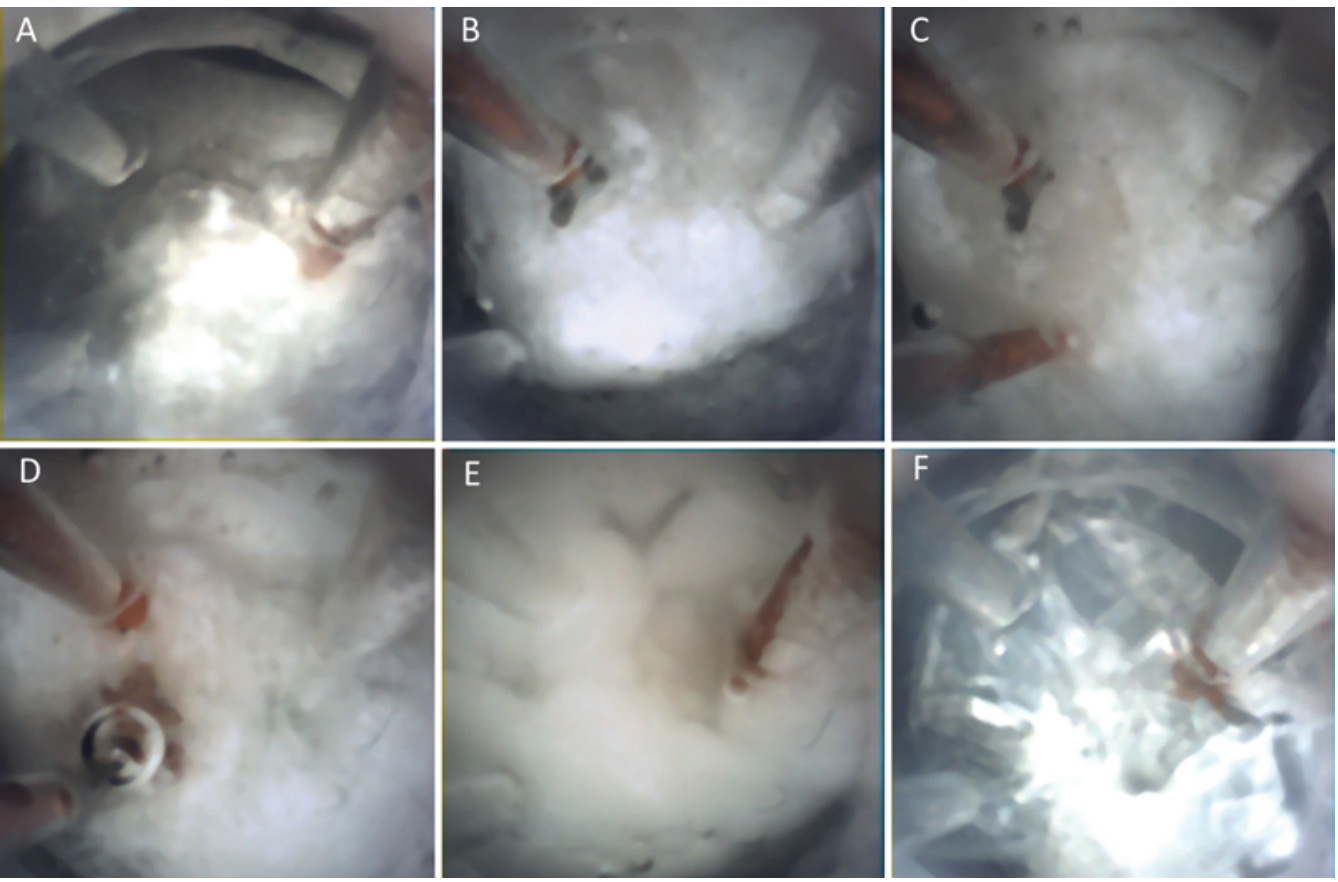

FIG. 9. Strategies resecting a colloid cyst phantom using a multiport silicone-tipped neuroendoscope with transparent channels within a distal silicone optical window (A). Endoscopic graspers for holding the capsule (B and $\mathbf{C})$. Suction and irrigation (D and $E$ ) used to empty cyst contents from the capsule $(\mathbf{F})$. 

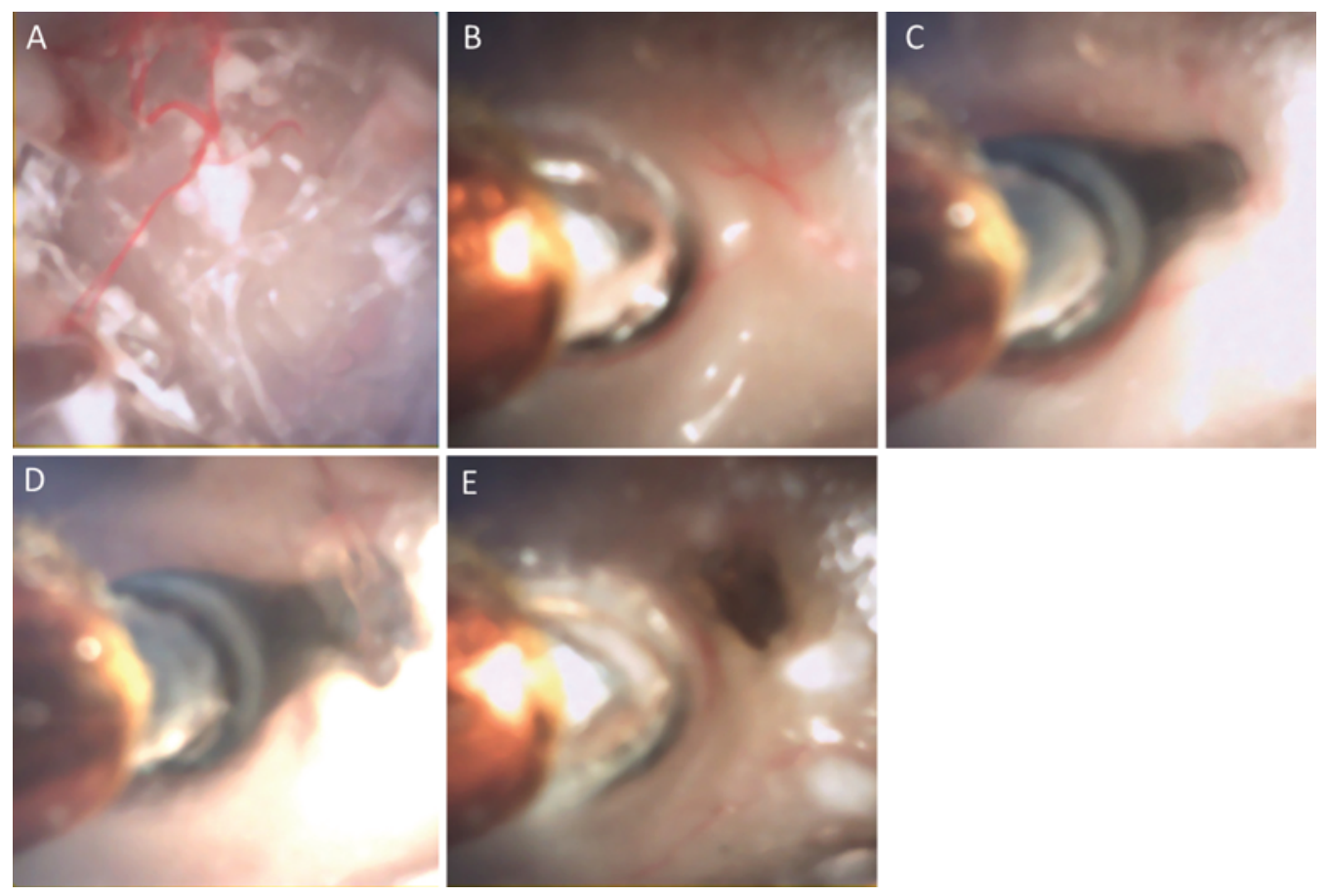

FIG. 10. Close-up tip port view (A) of the membranous capsule of the colloid cyst phantom. Side port septostomy steps using the novel neuroendoscope: advancing the endoscope toward the septum (B), emerging Bugbee probe (C), coagulation of the septum (D), and the site of fenestration (E).

mors and even offer transtumoral stent placement for CSF diversion, for example, third ventricular and aqueductal stents in craniopharyngiomas and tectal tumors, respectively. ${ }^{66}$

Posterior third ventricular lesions are more amenable to ventricular access when there is triventricular hydrocephalus resulting from aqueductal obstruction and widening of one or both foramina of Monro. ${ }^{15,53}$ An optimal trajectory between the hairline and Kocher's point is often used for biopsy of the lesion combined with an ETV. Morota and Ogiwara have proposed another trajectory using a flexible endoscope over the interthalamic adhesions in the third ventricle. ${ }^{55}$ Our current endoscope prototype has multiple channels at the tip; similarly, a modified design with a multichannel side port located very close to the tip of the endoscope would enable the surgical management of concurrent lesions in lateral and third ventricles, offering minimal traction at the foramen of Monro. ${ }^{19,20,73}$

Beyond hydrocephalus, our neuroendoscope can also be used in endoscope-assisted microsurgical cisternal procedures such as corpus callosotomy in a minimally invasive manner with limited brain retraction. Furthermore, for neurosurgeons in remote underprivileged communities without access to stereotaxy, this device can be used in a disposable manner to perform an endoscope-assisted microsurgical procedure. ${ }^{94,95}$

\section{MR Compatibility}

We have shown that the size of the MRI artifact corresponds to the size of the endoscope itself, providing the ability to image tissue adjacent to each imaging port. Since most endoscopes are not MR compatible, endos- copy and MRI guidance are typically viewed as mutually exclusive. ${ }^{77,78}$ Intraoperative removal and reinsertion of the endoscope to perform MRI is deemed too risky in terms of iatrogenic hemorrhages. However, the combined use of MRI and endoscopy can provide the benefits of stereotaxy as well as real-time optical imaging. ${ }^{70,81,84,85} \mathrm{Cur}-$ rently, it is common practice to co-register the endoscope with preoperative MRI used for trajectory planning. In contrast, MRI with our new endoscope within the ventricular system can provide real-time continuous imaging and compensate for brain shift that occurs with CSF egress during ventriculoscopy. This is especially critical in treating ventricles scarred from prior infection or inflammation or periventricular tumors with a diffuse or ill-defined brain-tumor interface, as in gliomas or central neurocytomas. ${ }^{34,38}$

The MR compatibility of our new endoscope renders it suitable to treat complex or multiloculated hydrocephalus associated with multiplanar septations or cystic malformations of periventricular brain. ${ }^{64}$ Solely depending on endoscopic luminal anatomy can cause inadvertent neurovascular injuries especially in an atrophic brain with deformed ventricular anatomy. ${ }^{34}$ Magnetic resonance imaging guidance can offer safe, optimal, and tailored endoscopic fenestration in these cases (ventriculocystostomy, cystocystostomy, cystoventriculostomy, or cystoventriculocisternostomy as mandated) and precise insertion of a ventriculoperitoneal shunt in selected cases, avoiding catheter misplacement in a cul-de-sac. The same technology can be effectively used for intraventricular stent procedures (aqueductoplasty and stenting), as well as intratumoral stenting (in craniopharyngiomas sealing off the prior ETV 

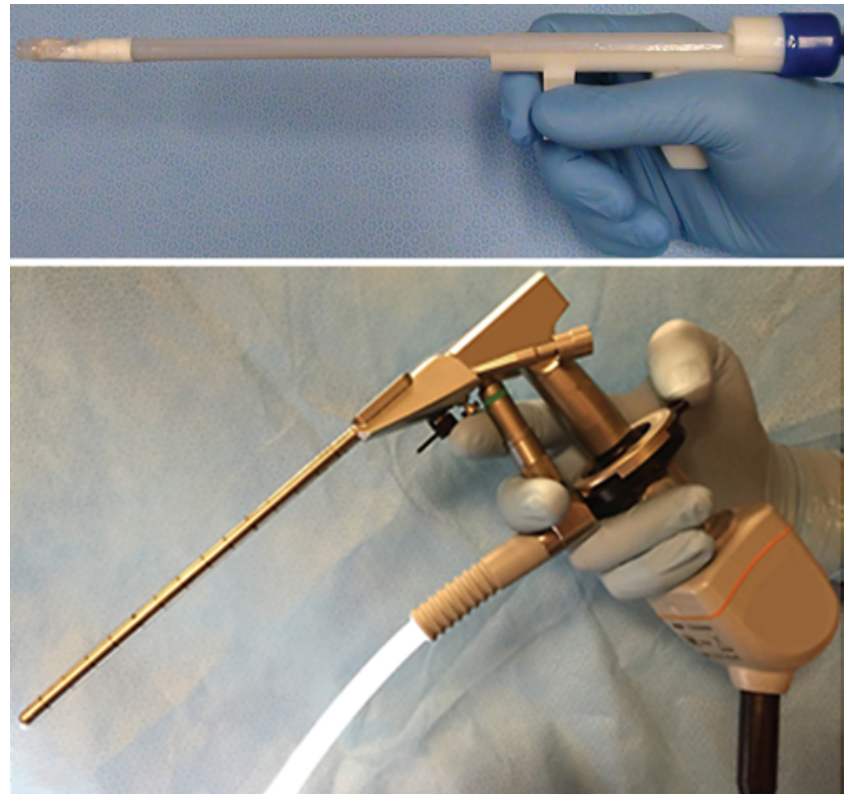

FIG. 11. Upper: New light-weight $(<50 \mathrm{~g})$ multiport neuroendoscope. Lower: Currently used clinical neuroendoscope with an "inverted pendulum effect" due to the heavy proximal camera and light-cable attachments, weighing over $500 \mathrm{~g}$ in total.

or in a posterior third ventricular region tumor occluding the aqueduct). 3,9,21,29,33,49,66,69,83 Magnetic resonance compatibility can be helpful in treating intraventricular neurocysticercosis as well as juxtaventricular parenchymal cystic changes such as tumefactive enlargement of thalamopeduncular Virchow-Robin spaces., ${ }^{3,24}$

Intraoperative MRI technology has revolutionized neurosurgery in the past 2 decades, especially with the advent of MR-compatible probe drivers (ClearPoint) and transventricular laser ablation of periventricular lesions via NeuroBlate and Visualase. ${ }^{52,62,65}$ The indications for real-time MR-guided laser treatment have extended from focal metastatic and glial neoplasms to refractory cerebral edema, radiation necrosis, lesional epilepsy, and even cavernous malformations in the brain. ${ }^{11,12,26,50,52,65,68,97}$ The paraventricular tumors, especially those in the thalamic region as well as those in which maximal safe resection is not feasible, have become amenable to MR-guided laser treatment. ${ }^{75,89,93,97}$ These technologies, however, provide real-time yet noncontinuous MRI during the procedure. ${ }^{79}$ In a majority of these MR-guided laser therapies, surgeons use a skull bolt to deliver the laser probe via a single bur hole in the skull. However, for multiple lesions that are not accessible, a second trajectory is employed via a second skull entry point. A new 4.5-mm on-trajectory twist drill hole is typically made for additional trajectories. Surgeons generally try to avoid a trajectory through the cerebral ventricles for treating parenchymal lesions, but violation of a ventricular wall often does happen inadvertently with stereotactic errors. While using our device for ventriculoscopy, the surgeon uses a familiar preplanned bur hole as an entry point and takes advantage of the appropriate side ports for both visualization and penetration of the periventricular lesion that needs laser ablation. The ability to use the front and side ports interchangeably and concurrently, as well as multiple degrees of freedom in the ventricular cavity (translation, rotation), can enhance the safety and feasibility of targeting juxtaventricular lesions for laser therapy.

Magnetic resonance-guided neuroendoscopy using our device offers the combined advantages of stereotactic biopsy (whereby sampling the most representative or contrast-enhancing area of a heterogeneous MRI target can be achieved) and direct vision of the target. ${ }^{16,35,63,80}$ In addition, biopsy or resection of a lesion under endoscopic imaging could be improved by optical imaging of live tumor margins and could further enhance safety by enabling real-time visualization of intraprocedural hemorrhage and tool-based hemostasis, as in cases of vascular tumors or postinflammatory hydrocephalus with vascularized membranes.

\section{Optical Window}

With our design, we investigated the utility of an optically clear silicone window on the tip imaging port and demonstrated 2 potential advantages. First, the optical window enables visualization of inserted tools before they emerge from the endoscope tip. In addition, the optical window can be used to gently press against tissue and thus displace any fluid, including blood, between the window and this tissue. During near contact the suction and irrigation channels can still function, whereas during full contact there is clear vision and soft pressure at the bleeding site offering contact hemostasis. This transparent window is a built-in feature of our neuroendoscope, unlike a separate transparent sheath or trocar. ${ }^{56,60}$

Intraventricular hemorrhage can be a fatal complication from endoscopic neurosurgical procedures. ${ }^{47}$ Bleeding inside a ventricle during surgery is now typically managed through local warm saline irrigation, by promoting vasospasm and thus hemostasis. We designed the new endoscope with a soft silicone tip, which can exert even soft contact at the bleeding site, akin to the application of Gelfoam and cottonoid over bleeding veins and dural venous sinuses. Since the majority of intraventricular hemostasis during neurosurgical operations is performed without tissue contact, warm saline irrigation is the primary method of controlling minor hemorrhages, while bipolar coagulation is used for larger bleeding sites. Our new endoscope can offer focal soft contact pressure at the bleeding sites, especially venous hemorrhage.

\section{Endoscopic Imaging}

Endoscopic imaging systems are comprised of a lens system, a camera, and the associated electronics. The major difference between current rigid and flexible endoscopes is the optical components used to transmit the image from the objective lenses at the tip to the camera at the base. ${ }^{42}$ Rigid endoscopes employ a set of relay lenses, typically rod lenses, whereas flexible endoscopes employ an optical fiber bundle. Since each fiber transmits one pixel of the image, resolution is limited by fiber size and by the number of fibers in the bundle. Since the fibers have a finite size and are round, they produce an image with reduced resolution and clarity in comparison with the optics 
of a rigid endoscope. In our endoscope design, CMOS chip cameras are positioned directly at the port, and the image is transmitted electronically as a digital signal through the endoscope body to the frame grabber electronics and image display computer. Consequently, our designs do not employ either relay lenses or fiber bundles.

Current endoscopes rely on 2 camera technologies: CCDs and CMOSs. We have used a CMOS sensor, each pixel has its own charge-to-voltage conversion, and the sensor often also includes amplifiers, noise correction, and digitization circuits so that the chip outputs digital bits. This lowers camera cost while providing faster readout, lower power consumption, higher noise immunity, and a smaller system size. The CMOS camera used in our prototype, at $1 \mathrm{~mm}$ on a side, is among the smallest currently available and provides an image size of $250 \times 250$ $=62,500$ pixels. For comparison, a fiber bundle of comparable cross-section contains only 20,000 fibers/pixels. ${ }^{28}$ Thus, the image quality of our endoscope lies between that of existing rigid and flexible neuroendoscopes (Fig. 7).

While image resolution is limited by the size of the photodiodes that can be manufactured, image quality also depends on the camera lens(es) and on the image processing software. Both can be optimized on an applicationspecific basis, and chip-on-tip endoscopes have been clinically introduced in other fields such as general surgery, urology, and gynecology. ${ }^{28,42,46}$ Similar to our design and in contrast to existing neuroendoscopes, these devices are "focus-free" designs wherein their lens systems have been optimized to provide a sharp image over a large depth of field.

\section{Device Limitations}

The current design is intended as a proof-of-concept prototype, fabricated using materials and techniques available in our laboratory, and so has not benefited from the extensive product development cycle of an actual clinical device. Limitations of the current prototype relate to image quality and working channel size, as described below.

While the use of chip cameras enables multiple imaging ports, image quality is less than what is offered by the single imaging port of a standard scope. Specifically, image quality is reduced in air and at viewing distances greater than $2 \mathrm{~cm}$. Just as smart phone cameras have had continued improvements, it is likely that the stated limitations of our prototype can be mitigated through the use of improved lenses, the addition of antireflective coatings to the optical window, optimization of the relative configuration of the camera, LED, and window surface to minimize internal reflections, and tuning of the image processing software for neurosurgical visualization.

The size of the working channels in the current prototype is small and must be enlarged. In any scope, including the proposed design, the number and diameter of the channels are constrained by the scope diameter. For example, Fig. 12 depicts the cross-section of a standard scope as shared by the optical channel and the working channels (Aesculap MINOP system FF399R). Note that while a traditional rod lens runs the entire length of the scope, the camera and LED pair (shown superimposed on the optical channel in Fig. 12) only consume a few millimeters of

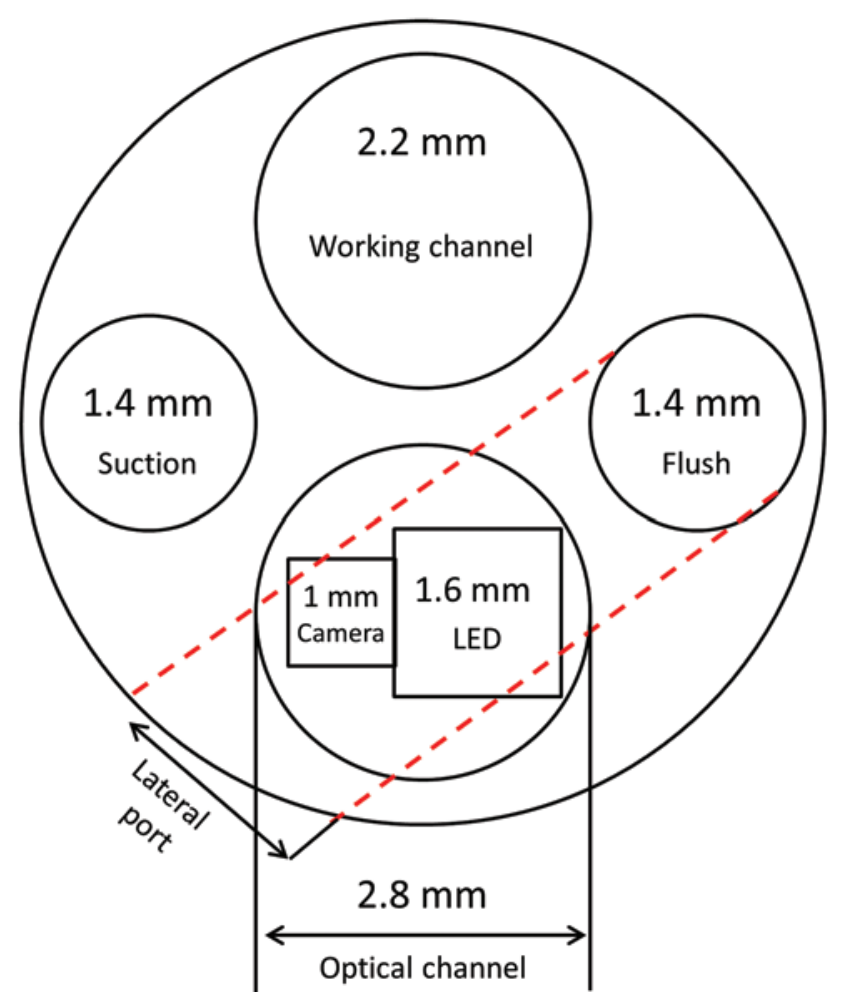

FIG. 12. Comparison of hardware arrangement within cross-sections of a 6-mm rigid endoscope with a multiport neuroendoscope. A conventional rod lens endoscope with a $2.8-\mathrm{mm}$ scope channel can easily accommodate a 2.6-mm construct (1.6-mm LED and 1-mm chip-on-tip camera) of the multiport endoscope. The addition of a side port working channel with concurrent imaging tends to use up more of the crosssectional area.

scope length. Thus, this portion of the cross-section is free to be used as a working channel terminating at a proximal imaging port. The constraint is that the working channel leading to a proximal port located on a lateral surface must curve inside the cross-section. For example, the dashed lines indicate how one of the 1.4-mm working channels can be connected to a lateral port. Such a design, while requiring sufficiently flexible tools for the lateral port, would include the same number and size of working channels as in a current rigid scope.

We have not performed sterilization testing of the multiport scope; however, its components are compatible with gas sterilization. Furthermore, existing endoscopes using chip cameras can be sterilized by autoclave, ethylene oxide (EtO), or STERRAD. ${ }^{72}$

\section{Conclusions}

A multiport MR-compatible neuroendoscope can be a versatile tool in treating a wide spectrum of intraventricular and periventricular pathologies in the brain. This peel-packed plug-and-play device does not cause the typical torque-related "inverted pendulum effect" or heavily compromise on the visual quality (Fig. 13). Magnetic resonance compatibility allows for periventricular tumor resection and management of complex hydrocephalus, ex- 


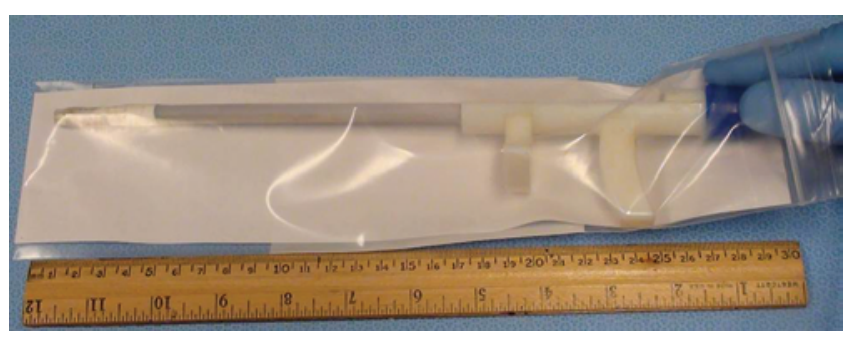

FIG. 13. Disposable "plug-and-play" MR-compatible multiport neuroendoscope: original prototype.

tending the spectrum of ventriculoscopic approaches in the brain. Additional clinical advantages of this landmark endoscope design stem from the utilization of a "diver's mask" silicone window, which allows soft contact hemostasis and visualization of instruments coming through its transparent channels. More experiments are required to validate its use in treating cisternal brain pathologies and intraparenchymal lesions (tumors and hematomas) and in skull base surgeries.

\section{Acknowledgments}

This work was partially supported by the NIH Grant No. R01HL124020.

\section{References}

1. Akbari SHA, Holekamp TF, Murphy TM, Mercer D, Leonard JR, Smyth MD, et al: Surgical management of complex multiloculated hydrocephalus in infants and children. Childs Nerv Syst 31:243-249, 2015

2. Andrews RJ, Bringas JR: A review of brain retraction and recommendations for minimizing intraoperative brain injury. Neurosurgery 33:1052-1064, 1993

3. Apuzzo ML, Dobkin WR, Zee CS, Chan JC, Giannotta SL, Weiss MH: Surgical considerations in treatment of intraventricular cysticercosis. An analysis of 45 cases. J Neurosurg 60:400-407, 1984

4. Ataollahi A, Berra I, Vasilyev NV, Machaidze Z, Dupont PE: Cardioscopic tool delivery instrument for beating-heart surgery. IEEE/ASME Trans Mechatron 21:584-590, 2016

5. Bakshi A, Patir R, Bakshi A, Banerji AK: A multifunctional, modified rigid neuroendoscopic system: clinical experience with 83 procedures. Technical note. J Neurosurg 99:421425, 2003

6. Balossier A, Blond S, Touzet G, Lefranc M, de Saint-Denis T, Maurage CA, et al: Endoscopic versus stereotactic procedure for pineal tumour biopsies: Comparative review of the literature and learning from a 25 -year experience. Neurochirurgie 61:146-154, 2015

7. Bergsneider M: Complete microsurgical resection of colloid cysts with a dual-port endoscopic technique. Neurosurgery 60 (2 Suppl 1):ONS33-ONS43, 2007

8. Berlis A, Vesper J, Ostertag C: Stent placement for intracranial cysts by combined stereotactic/endoscopic surgery. Neurosurgery 59 (4 Suppl 2):ONS474-ONS480, 2006

9. Biswas T, Luu T: In vivo MR measurement of refractive index, relative water content and $\mathrm{T} 2$ relaxation time of various brain lesions with clinical application to discriminate brain lesion. Int J Radiol 13: 1-9, 2011

10. Breimer GE, Bodani V, Looi T, Drake JM: Design and evaluation of a new synthetic brain simulator for endoscopic third ventriculostomy. J Neurosurg Pediatr 15:82-88, 2015

11. Carpentier A, Chauvet D, Reina V, Beccaria K, Leclerq $\mathrm{D}$, McNichols RJ, et al: MR-guided laser-induced thermal therapy (LITT) for recurrent glioblastomas. Lasers Surg Med 44:361-368, 2012

12. Carpentier A, McNichols RJ, Stafford RJ, Itzcovitz J, Guichard JP, Reizine D, et al: Real-time magnetic resonance-guided laser thermal therapy for focal metastatic brain tumors. Neurosurgery 63 (1 Suppl 1):ONS21ONS29, 2008

13. Chamiraju P, Bhatia S, Sandberg DI, Ragheb J: Endoscopic third ventriculostomy and choroid plexus cauterization in posthemorrhagic hydrocephalus of prematurity. $\mathbf{J}$ Neurosurg Pediatr 13:433-439, 2014

14. Chernov MF, Kamikawa S, Yamane F, Ishihara S, Kubo O, Hori T: Neurofiberscopic biopsy of tumors of the pineal region and posterior third ventricle: indications, technique, complications, and results. Neurosurgery 59:267-277, 2006

15. Chibbaro S, Di Rocco F, Makiese O, Reiss A, Poczos P, Mirone G, et al: Neuroendoscopic management of posterior third ventricle and pineal region tumors: technique, limitation, and possible complication avoidance. Neurosurg $\operatorname{Rev}$ 35:331-340, 2012

16. Constantini S, Mohanty A, Zymberg S, Cavalheiro S, Mallucci C, Hellwig D, et al: Safety and diagnostic accuracy of neuroendoscopic biopsies: an international multicenter study. J Neurosurg Pediatr 11:704-709, 2013

17. Decq P: Endoscopy or microsurgery: is the never-ending debate concerning the choice of surgical strategy for colloid cysts of the third ventricle still a topical issue or has it been resolved? World Neurosurg 80:498-499, 2013

18. Di Ieva A, Tam M, Tschabitscher M, Cusimano MD: A journey into the technical evolution of neuroendoscopy. World Neurosurg 82:e777-e789, 2014

19. Eastwood KW, Bodani VP, Drake JM: Three-dimensional simulation of collision-free paths for combined endoscopic third ventriculostomy and pineal region tumor biopsy: implications for the design specifications of future flexible endoscopic instruments. Op Neurosurg [epub ahead of print], 2015

20. Eastwood KW, Looi T, Naguib HE, Drake JM: Design optimization of neuroendoscopic continuum instruments for third ventriculostomy and tumor biopsy. Conf Proc IEEE Eng Med Biol Soc 2015:4853-4856, 2015

21. El Refaee E, Baldauf J, Schroeder HW: Bilateral occlusion of the foramina of Monro after third ventriculostomy. J Neurosurg 116: 1333-1336, 2012

22. Ellenbogen RG, Moores LE: Endoscopic management of a pineal and suprasellar germinoma with associated hydrocephalus: technical case report. Minim Invasive Neurosurg 40: 13-16, 1997

23. Enchev Y, Oi S: Historical trends of neuroendoscopic surgical techniques in the treatment of hydrocephalus. Neurosurg Rev 31:249-262, 2008

24. Endo H, Fujimura M, Watanabe M, Tominaga T: Neuroendoscopic management of mesencephalic intraparenchymal cyst: a case report. Surg Neurol 71:107-110, 2009

25. Engh JA, Lunsford LD, Amin DV, Ochalski PG, FernandezMiranda J, Prevedello DM, et al: Stereotactically guided endoscopic port surgery for intraventricular tumor and colloid cyst resection. Neurosurgery 67 (3 Suppl Operative):ons 198-ons205, 2010

26. Fabiano AJ, Alberico RA: Laser-interstitial thermal therapy for refractory cerebral edema from post-radiosurgery metastasis. World Neurosurg 81:652.e1-652.e4, 2014

27. Fiorindi A, Longatti P: A restricted neuroendoscopic approach for pathological diagnosis of intraventricular 
and paraventricular tumours. Acta Neurochir (Wien) 150:1235-1239, 2008

28. Friedman GN, Grannan BL, Nahed BV, Codd PJ: Initial experience with high-definition camera-on-a-chip flexible endoscopy for intraventricular neurosurgery. World Neurosurg 84:2053-2058, 2015

29. Fritsch MJ, Schroeder HW: Endoscopic aqueductoplasty and stenting. World Neurosurg 79 (2 Suppl):S20.e15-S20. e8, 2013

30. Gosline AH, Vasilyev NV, Butler EJ, Folk C, Cohen A, Chen R, et al: Percutaneous intracardiac beating-heart surgery using metal MEMS tissue approximation tools. Int J Rob Res 31:1081-1093, 2012

31. Güttler F, Rump J, Teichgräber U, Seebauer C, Winterwerber K, inventors: Endoscopic multifunction device for medical therapy. International Patent WO2013131578 A1. September 12, 2013.

32. Hamada H, Hayashi N, Kurosaki K, Kurimoto M, Endo S: Technical considerations of endoscopic septostomy using a biportal approach in a case of hydrocephalus associated with tuberous sclerosis. Minim Invasive Neurosurg 52:79-82, 2009

33. Hana T, Tanaka S, Shin M, Mukasa A, Kugasawa K, Saito $\mathrm{N}$ : Neuroendoscopic ventriculocisternostomy with stent placement for trapped temporal horn after the resection of glioblastoma. World Neurosurg 84:2078.e5-2078.e8, 2015

34. Hayashi N, Hamada H, Umemura K, Kurosaki K, Kurimoto M, Endo S: Transparent endoscopic sheath and rigid-rod endoscope used in endoscopic third ventriculostomy for hydrocephalus in the presence of deformed ventricular anatomy. J Neurosurg 104 (5 Suppl):321-325, 2006

35. Hayashi N, Murai H, Ishihara S, Kitamura T, Miki T, Miwa T, et al: Nationwide investigation of the current status of therapeutic neuroendoscopy for ventricular and paraventricular tumors in Japan: clinical article. J Neurosurg 115: 1147-1157, 2011

36. Hernández-León O, Rodríguez-Villalonga OL, PérezNogueira FR, Guillén-Cánovas EJ, Alvarez-Toledo N, Lemus-Saraceni A: [Endoscopic approach to ventricular atrium for biopsy of pineal region tumour: case report.] Neurocirugia (Ástur) 25:43-47, 2014 (Span)

37. Ho AL, Pendharkar AV, Sussman ES, Ravikumar VK, Li GH: Dual-trajectory approach for simultaneous cyst fenestration and endoscopic third ventriculostomy for treatment of a complex third ventricular arachnoid cyst. Cureus 7:e253, 2015

38. Idris Z, Ghani ARI, Idris B, Muzaimi M, Awang S, Pal HK, et al: Neuronavigation-guided endoscopic management of a pineal region tumour with obscured floor of the third ventricle: case report. Minim Invasive Neurosurg 54:125127,2011

39. Jho HD, Alfieri A: Endoscopic removal of third ventricular tumors: a technical note. Minim Invasive Neurosurg 45:114-119, 2002

40. Jolesz FA: Interventional and intraoperative MRI: a general overview of the field. J Magn Reson Imaging 8:3-7, 1998

41. Jolesz FA, Morrison PR, Koran SJ, Kelley RJ, Hushek SG, Newman RW, et al: Compatible instrumentation for intraoperative MRI: expanding resources. J Magn Reson Imaging 8:8-11, 1998

42. Kahrs LA, McRackan TR, Labadie RF: Intracochlear visualization: comparing established and novel endoscopy techniques. Otol Neurotol 32:1590-1595, 2011

43. Knaus H, Matthias S, Koch A, Thomale UW: Single burr hole endoscopic biopsy with third ventriculostomymeasurements and computer-assisted planning. Childs Nerv Syst 27:1233-1241, 2011

44. Kulkarni AV, Riva-Cambrin J, Browd SR, Drake JM, Holubkov R, Kestle JR, et al: Endoscopic third ventriculostomy and choroid plexus cauterization in infants with hydrocephalus: a retrospective Hydrocephalus Clinical Research Network study. J Neurosurg Pediatr 14:224-229, 2014

45. Lewis AI, Crone KR, Taha J, van Loveren HR, Yeh HS, Tew JM Jr: Surgical resection of third ventricle colloid cysts. Preliminary results comparing transcallosal microsurgery with endoscopy. J Neurosurg 81:174-178, 1994

46. Lusch A, Abdelshehid C, Hidas G, Osann KE, Okhunov $\mathrm{Z}, \mathrm{McD}$ ougall $\mathrm{E}$, et al: In vitro and in vivo comparison of optics and performance of a distal sensor ureteroscope versus a standard fiberoptic ureteroscope. J Endourol 27:896-902, 2013

47. Luther N, Cohen A, Souweidane MM: Hemorrhagic sequelae from intracranial neuroendoscopic procedures for intraventricular tumors. Neurosurg Focus 19(1):E9, 2005

48. Mangano FT, Limbrick Jr, DD, Leonard JR, Park TS, Smyth MD: Simultaneous image-guided and endoscopic navigation without rigid cranial fixation: application in infants: technical case report. Op Neurosurg 58 (4 Suppl 2):ONSE377, 2006

49. Marx S, Fleck SK, El Refaee E, Manwaring J, Vorbau C, Fritsch MJ, et al: Neuroendoscopic stent placement for cerebrospinal fluid pathway obstructions in adults. J Neurosurg 8:1-9, 2016

50. McCracken DJ, Willie JT, Fernald BA, Saindane AM, Drane DL, Barrow DL, et al: Magnetic resonance thermometry-guided stereotactic laser ablation of cavernous malformations in drug-resistant epilepsy: imaging and clinical results. Neurosurgery [epub ahead of print], 2015

51. McLaughlin N, Prevedello DM, Engh J, Kelly DF, Kassam $\mathrm{AB}$ : Endoneurosurgical resection of intraventricular and intraparenchymal lesions using the port technique. World Neurosurg 79:S18.e1-S18.e8, 2012

52. Mohammadi AM, Schroeder JL: Laser interstitial thermal therapy in treatment of brain tumors - the NeuroBlate System. Expert Rev Med Devices 11:109-119, 2014

53. Morgenstern PF, Souweidane MM: Pineal region tumors: simultaneous endoscopic third ventriculostomy and tumor biopsy. World Neurosurg 79 (2 Suppl):S18.e9-S18.e13, 2013

54. Mori R, Joki T, Nonaka Y, Ikeuchi S, Abe T: Parallel insertion endoscopic technique for precise catheter placement in cystic craniopharyngiomas. J Neurol Surg A Cent Eur Neurosurg 75:442-446, 2014

55. Morota N, Ogiwara H: Supra-interthalamic adhesion approach: a modified surgical approach for neuroendoscopic biopsy of pineal tumors. Childs Nerv Syst 30:1565-1570, 2014

56. Nishihara T, Teraoka A, Morita A, Ueki K, Takai K, Kirino T: A transparent sheath for endoscopic surgery and its application in surgical evacuation of spontaneous intracerebral hematomas. Technical note. J Neurosurg 92:1053-1055, 2000

57. Norris A, DeGroot J, Nishida F, Pernisz U, Kushibiki N, Ogawa T: Silicone Materials for Optical Applications. Midland, MI: Dow Corning Corporation, 2003 (http://www.dowcorning.com.cn/zh_CN/content/ publishedlit/75-1007-01_single.pdf)

58. Ogiwara H, Morota N: Flexible endoscopy for management of intraventricular brain tumors in patients with small ventricles. J Neurosurg Pediatr 14:490-494, 2014

59. Ogura K, Tachibana E, Aoshima C, Sumitomo M: New microsurgical technique for intraparenchymal lesions of the brain: transcylinder approach. Acta Neurochir (Wien) 148: 779-785, 2006

60. Oi S, Abdullah SH: New transparent peel-away sheath with neuroendoscopic orientation markers. Technical note. J Neurosurg 107:1244-1247, 2007 
61. Oka K, Yamamoto M, Nagasaka S, Tomonaga M: Endoneurosurgical treatment for hydrocephalus caused by intraventricular tumors. Childs Nerv Syst 10:162-166, 1994

62. Ostrem JL, Ziman N, Galifianakis NB, Starr PA, Luciano MS, Katz M, et al: Clinical outcomes using ClearPoint interventional MRI for deep brain stimulation lead placement in Parkinson's disease. J Neurosurg 124:908916, 2016

63. Otsuki T, Jokura H, Yoshimoto T: Stereotactic guiding tube for open-system endoscopy: a new approach for the stereotactic endoscopic resection of intra-axial brain tumors. Neurosurgery 27:326-330, 1990

64. Paraskevopoulos D, Biyani N, Constantini S, BeniAdani L: Combined intraoperative magnetic resonance imaging and navigated neuroendoscopy in children with multicompartmental hydrocephalus and complex cysts: a feasibility study. J Neurosurg Pediatr 8:279-288, 2011

65. Patel P, Patel NV, Danish SF: Intracranial MR-guided laserinduced thermal therapy: single-center experience with the Visualase thermal therapy system. J Neurosurg [epub ahead of print January 1, 2016. DOI: 10.3171/2015.7.JNS15244]

66. Pitskhelauri DI, Konovalov AN, Kopachev DN, Samborsky DI, Melnikova-Pitskhelauri TV: Microsurgical third ventriculostomy with stenting in intrinsic brain tumors involving anterior third ventricle. World Neurosurg 77:785.e3-785.e9, 2012

67. Procaccini E, Dorfmüller G, Fohlen M, Bulteau C, Delalande O: Surgical management of hypothalamic hamartomas with epilepsy: the stereoendoscopic approach. Neurosurgery 59 (4 Suppl 2):ONS336-ONS346, 2006

68. Rao MS, Hargreaves EL, Khan AJ, Haffty BG, Danish SF: Magnetic resonance-guided laser ablation improves local control for postradiosurgery recurrence and/or radiation necrosis. Neurosurgery 74:658-667, 2014

69. Roberti F, Magram G: Fiberscopic fenestration and prophylactic stenting of periaqueductal cysts: technical report on three cases. Minim Invasive Neurosurg 48:202206, 2005

70. Rohde V, Behm T, Ludwig H, Wachter D: The role of neuronavigation in intracranial endoscopic procedures. Neurosurg Rev 35:351-358, 2012

71. Roth J, Constantini S: Combined rigid and flexible endoscopy for tumors in the posterior third ventricle. J Neurosurg 122:1341-1346, 2015

72. Sabnis RB, Bhattu A, Vijaykumar M: Sterilization of endoscopic instruments. Curr Opin Urol 24:195-202, 2014

73. Sangra M, Clark S, Hayhurst C, Mallucci C: Electromagnetic-guided neuroendoscopy in the pediatric population. J Neurosurg Pediatr 3:325-330, 2009

74. Schroeder HW: A new multipurpose ventriculoscope. Neurosurgery 62:489-492, 2008

75. Schroeder JL, Missios S, Barnett GH, Mohammadi AM: Laser interstitial thermal therapy as a novel treatment modality for brain tumors in the thalamus and basal ganglia. Photonics Lasers Med 3:151-158, 2014

76. Schulz M, Bohner G, Knaus H, Haberl H, Thomale UW: Navigated endoscopic surgery for multiloculated hydrocephalus in children. J Neurosurg Pediatr 5:434442, 2010

77. Shellock FG: Compatibility of an endoscope designed for use in interventional MR imaging procedures. AJR Am J Roentgenol 171:1297-1300, 1998

78. Shellock FG: MRI safety of instruments designed for interventional MRI: assessment of ferromagnetism, heating, and artifacts, in Workshop on New Insights into Safety and Compatibility Issues Affecting In Vivo MR, Syllabus. Concord, CA: International Society of Magnetic Resonance in Medicine, 1998, p 39
79. Sloan AE, Ahluwalia MS, Valerio-Pascua J, Manjila S, Torchia MG, Jones SE, et al: Results of the NeuroBlate System first-in-humans Phase I clinical trial for recurrent glioblastoma: clinical article. J Neurosurg 118:1202-1219, 2013

80. Somji M, Badhiwala J, McLellan A, Kulkarni AV: Diagnostic yield, morbidity, and mortality of intraventricular neuroendoscopic biopsy: systematic review and metaanalysis. World Neurosurg 85:315-24.e2, 2016

81. Stark AM, Schwartz F, Mehdorn M, Nabavi A: Neuroendoscopy and high-field intraoperative MRI: first experience. J Neurol Surg A Cent Eur Neurosurg 75:371375,2014

82. Stone SS, Warf BC: Combined endoscopic third ventriculostomy and choroid plexus cauterization as primary treatment for infant hydrocephalus: a prospective North American series. J Neurosurg Pediatr 14:439-446, 2014

83. Suri A, Goel RK, Ahmad FU, Vellimana AK, Sharma BS, Mahapatra AK: Transventricular, transaqueductal scope-in-scope endoscopic excision of fourth ventricular neurocysticercosis: a series of 13 cases and a review. J Neurosurg Pediatr 1:35-39, 2008

84. Sutherland CS, Kelly JJ, Morrish W, Sutherland GR: Identification of disappearing brain lesions with intraoperative magnetic resonance imaging prevents surgery. Neurosurgery 67:1061-1065, 2010

85. Sutherland GR, Latour I, Greer AD: Integrating an imageguided robot with intraoperative MRI: a review of the design and construction of neuroArm. IEEE Eng Med Biol Mag 27:59-65, 2008

86. Tabakow P, Czyz M, Jarmundowicz W, Zub W: Neuroendoscopy combined with intraoperative lowfield magnetic imaging for treatment of multiloculated hydrocephalus in a 7-month-old infant: technical case report. Minim Invasive Neurosurg 54:138-141, 2011

87. Tamburrini G, Frassanito P, Massimi L, Caldarelli M, Di Rocco C: Endoscopic septostomy through a standard precoronal ventricular access: feasibility and effectiveness. Acta Neurochir (Wien) 154:1517-1522, 2012

88. Teo C, Kadrian D, Hayhurst C: Endoscopic management of complex hydrocephalus. World Neurosurg 79 (2 Suppl):S21.e1-S21.e7, 2013

89. Torres-Reveron J, Tomasiewicz HC, Shetty A, Amankulor NM, Chiang VL: Stereotactic laser induced thermotherapy (LITT): a novel treatment for brain lesions regrowing after radiosurgery. J Neurooncol 113:495-503, 2013

90. Vasilyev NV, Martinez JF, Freudenthal FP, Suematsu Y, Marx GR, del Nido PJ: Three-dimensional echo and videocardioscopy-guided atrial septal defect closure. Ann Thorac Surg 82:1322-1326, 2006

91. Vetõ F, Horváth Z, Dóczi T: Biportal endoscopic management of third ventricle tumors in patients with occlusive hydrocephalus: technical note. Neurosurgery 40:871-877, 1997

92. Vinas FC, Castillo C, Diaz FG: Microanatomical considerations for the fenestration of the septum pellucidum. Minim Invasive Neurosurg 41:20-26, 1998

93. Voigt JD, Barnett G: The value of using a brain laser interstitial thermal therapy (LITT) system in patients presenting with high grade gliomas where maximal safe resection may not be feasible. Cost Eff Resour Alloc 14:6, 2016

94. Warf BC: Hydrocephalus in Uganda: the predominance of infectious origin and primary management with endoscopic third ventriculostomy. J Neurosurg 102 (1 Suppl): 1-15, 2005

95. Warf BC, Campbell JW: Combined endoscopic third ventriculostomy and choroid plexus cauterization as 
primary treatment of hydrocephalus for infants with myelomeningocele: long-term results of a prospective intent-to-treat study in 115 East African infants. J Neurosurg Pediatr 2:310-316, 2008

96. Watanabe T, Sato T, Kishida Y, Ito E, Ichikawa M, Sakuma J, et al: Endoscopic resection of cystic pontine tumour: three case reports and a proposal for minimally invasive dualendoscopic surgery. Acta Neurochir (Wien) 156:11451150,2014

97. Willie JT, Laxpati NG, Drane DL, Gowda A, Appin C, Hao $\mathrm{C}$, et al: Real-time magnetic resonance-guided stereotactic laser amygdalohippocampotomy for mesial temporal lobe epilepsy. Neurosurgery 74:569-585, 2014

98. Yamamoto M, Oka K, Ikeda K, Tomonaga M: Percutaneous flexible neuroendoscopic ventriculostomy in patients with shunt malfunction as an alternative procedure to shunt revision. Surg Neurol 42:218-223, 1994

99. Yamamoto M, Oka K, Takasugi S, Hachisuka S, Miyake E, Tomonaga M: Flexible neuroendoscopy for percutaneous treatment of intraventricular lesions in the absence of hydrocephalus. Minim Invasive Neurosurg 40:139-143, 1997

100. Zhu XL, Gao R, Wong GKC, Wong HT, Ng RYT, Yu Y, et al: Single burr hole rigid endoscopic third ventriculostomy and endoscopic tumor biopsy: what is the safe displacement range for the foramen of Monro? Asian J Surg 36:74-82, 2013

\section{Disclosures}

Drs. Manjila, Mancattelli, Rosa, and Dupont are listed as coinventors on a patent application that includes material in this article.

\section{Author Contributions}

Conception and design: Dupont, Manjila, Mencattelli, Rosa, Price. Acquisition of data: all authors. Analysis and interpretation of data: all authors. Drafting the article: Dupont, Manjila, Mencattelli, Rosa. Critically revising the article: Dupont, Manjila, Mencattelli. Reviewed submitted version of manuscript: Manjila, Mencattelli. Administrative/technical/material support: Mencattelli.

\section{Correspondence}

Pierre E. Dupont, Department of Cardiovascular Surgery, Boston Children's Hospital, Harvard Medical School, 300 Longwood Ave., Enders 348, Boston, MA 02115. email: pierre.dupont@ childrens.harvard.edu. 